\title{
Status Report on
} Activities of the Systems Assessment Task Force, OECD-NEA Expert Group on Accident Tolerant Fuels for LWRs

Shannon M. Bragg-Sitton

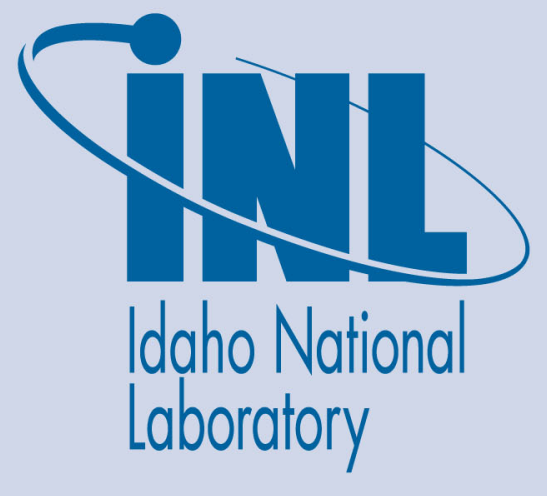

September 2017

The INL is a U.S. Department of Energy National Laboratory operated by Battelle Energy Alliance 


\section{DISCLAIMER}

This information was prepared as an account of work sponsored by an agency of the U.S. Government. Neither the U.S. Government nor any agency thereof, nor any of their employees, makes any warranty,

expressed or implied, or assumes any legal liability or responsibility for the accuracy, completeness, or usefulness, of any information, apparatus, product, or process disclosed, or represents that its use would not infringe privately owned rights. References herein to any specific commercial product, process, or service by trade name, trade mark, manufacturer, or otherwise, does not necessarily constitute or imply its endorsement, recommendation, or favoring by the U.S. Government or any agency thereof. The views and opinions of authors expressed herein do not necessarily state or reflect those of the U.S. Government or any agency thereof. 


\section{Status Report on Activities of the Systems Assessment Task Force, OECD-NEA Expert Group on Accident Tolerant Fuels for LWRs}

Shannon M. Bragg-Sitton

September 2017

Idaho National Laboratory

Idaho Falls, Idaho 83415

http://www.inl.gov

Prepared for the

U.S. Department of Energy

Office of Nuclear Energy

Under DOE Idaho Operations Office

Contract DE-AC07-05ID14517 
INL/EXT-17-43389 


\section{Status Report on the Activities of the Systems Assessment Task Force, OECD-NEA Expert Group on Accident Tolerant Fuels for LWRs}

\section{INTRODUCTION}

The Organization for Economic Cooperation and Development/Nuclear Energy Agency (OECD/NEA) Nuclear Science Committee approved the formation of an Expert Group on Accident Tolerant Fuel (ATF) for LWRs (EGATFL) in 2014. Chaired by Kemal Pasamehmetoglu, INL Associate Laboratory Director for Nuclear Science and Technology, the mandate for the EGATFL defines work under three task forces: (1) Systems Assessment, (2) Cladding and Core Materials, and (3) Fuel Concepts. Scope for the Systems Assessment task force (TF1) includes definition of evaluation metrics for ATF, technology readiness level definition, definition of illustrative scenarios for ATF evaluation, and identification of fuel performance and system codes applicable to ATF evaluation. The identification of irradiation facilities around the world that are being used, or are planned to be used, for the irradiation testing of ATF cladding and fuel materials was later added to the TF1 scope (April 2017). The Cladding and Core Materials (TF2) and Fuel Concepts (TF3) task forces have worked to identify gaps and needs for modeling and experimental demonstration; define key properties of interest; identify the data necessary to perform concept evaluation under normal conditions and illustrative scenarios; identify available infrastructure (internationally) to support experimental needs; and make recommendations on priorities. Where possible, considering proprietary and other export restrictions (e.g., International Traffic in Arms Regulations), the Expert Group has facilitated the sharing of data and lessons learned across the international group membership. The Systems Assessment task force is chaired by Shannon Bragg-Sitton (Idaho National Laboratory [INL], U.S.), the Cladding Task Force is chaired by Marie Moatti (Electricite de France [EdF], France), and the Fuels Task Force is chaired by a Masaki Kurata (Japan Atomic Energy Agency [JAEA], Japan). The original Expert Group mandate was established for June 2014 to June 2016. In April 2016 the Expert Group voted to extend the mandate one additional year to June 2017 in order to complete the task force deliverables; this request was subsequently approved by the Nuclear Science Committee. All reports are currently in final draft and will be submitted to NEA for final formatting/editing in October 2017. A final EGATFL meeting will be held at NEA Headquarters in Paris, France on November 2-3, 2017 to resolve any final comments on the task force reports. This report provides brief summary of the Systems Assessment Task Force deliverable report.

\section{SYSTEMS ASSESSMENT TASK FORCE SCOPE}

Scope for the EGATF Systems Assessment task force includes definition of evaluation metrics for ATF, technology readiness level definition, definition of illustrative scenarios for ATF evaluation, and identification of applicable fuel performance and system codes. The initial Task Force scope also included potential to perform parametric assessments of fuel performance to determine the most impactful parameters/properties on the fuel system performance and behaviors. Sub-tasks were grouped to manage the amount of work and to provide clear deliverables. At the April 2017 EGATFL meeting it was decided that the Task Force 1 report would also include a summary of irradiation facilities that either are being used or could be used for in-pile testing of ATF materials.

The Systems Assessment task force originally planned to deliver two reports:

1. Evaluation Metrics and Technology Readiness Level Definition

2. ATF Evaluation - Selected Illustrative Scenarios, Applicable Codes and Parametric Studies 
However, upon compilation of the information for the two reports it was decided that these efforts would be combined into a single deliverable report. Parametric studies were removed from the TF1 scope and, hence, are not included in the final deliverable, although recommendations for sensitivity studies are made in the document. However, a section was added on irradiation facilities that are available across the participating NEA member countries for ATF cladding and fuel irradiation. The final deliverable has been submitted to NEA for review such that it can be approved by the Expert Group at the planned November 2017 meeting.

The Systems Assessment Task Force report compiles an agreed set of evaluation metrics (including recommended evaluation tests) for ATF fuel and cladding; definition of technology readiness levels as they relate to fuel systems; definition of illustrative scenarios for both PWRs and BWRs that can be applied by each member organization to the expert group to ensure that evaluation results (performance trends) can be compared across multiple organizations; a summary of available fuel performance and codes that can be used to evaluate ATF performance, can be modified to evaluate ATF concepts, or are under development; and a summary of irradiation facilities for testing of ATF materials.

\subsection{Evaluation Metrics}

The ATF performance metrics and evaluation approach proposed within the U.S. were presented at the September 2014 EGATFL meeting as a starting point for an international set of ATF performance and evaluation metrics. This approach is documented in detail in FCRD-FUEL-2013-000264 (INL/EXT-1329957). Additionally, proposed metrics for France and Japan are being incorporated to develop the international document, with consensus achieved among all countries/organizations represented on the Task Force. The proposed evaluation metrics for the U.S. are available in summary form in Bragg-Sitton et al. (2016). This journal article additionally covers proposed weighting of different performance aspects considered in the technical evaluation. These weighting factors were developed with the assistance of the Industry Advisory Committee and were reviewed by the Independent Review Committee established for ATF prioritization.

It is clear in all discussions on ATF that all countries/organizations developing ATF seek to extend the fuel system "coping time" under severe accident conditions. However, it is not clear how much additional coping time is desired, nor is it clear how coping time is being defined by each organization. A key decision taken in the April 2016 EGATFL Task Force 1 meeting was to clearly define "coping time" for use in NEA evaluations of ATF performance. At the April 2016 meeting, it was agreed that ATF concepts will be evaluated based on their ability to increase the "fuel coping time" under design extension conditions, where coping time is defined as follows: ${ }^{1}$

\section{Fuel Coping Time:}

For a given accident scenario, the "fuel coping time" is the time lapse between departure from normal operation and the moment at which significant loss of geometry of the fuel assemblies occurs, such that the reactor core can no longer be cooled or the fuel cannot be removed from the reactor using currently available tools and procedures.

As defined, the magnitude/scope of the "loss of geometry" is not specified, as the specific amount of degradation that defines an uncoolable condition may differ somewhat for each reactor design. In determining the fuel coping time the "minimum unit" may be considered to be the fuel assembly, as a limited number of failed fuel rods is currently acceptable for operating reactors. Inclusion of the specification that assemblies should be removable from the core using currently available tools and procedures ensures that the coping time will be measured up to the point that the asset is still recoverable.

\footnotetext{
${ }^{1}$ Note that minor modifications were made to the definition of coping time following the April 2016 meeting and issuance of the 2016 Status Report on Activities of the Systems Assessment Task Force (INL/EXT-16-39786).
} 
Coping time could also be defined as the time during which public protection can be ensured, but the EGATFL definition provided here offers a more conservative approach. The latter calculation of a time to reach public impact is much more akin to a reactor system coping time, which would be highly reliant on safety systems that would allow for mitigating actions.

Note that each fuel system concept should have an associated failure modes and effects analysis (FMEA) conducted to determine the onset of failure modes that would lead to unacceptable conditions or performance. Additionally, the appropriate coping time for comparison of fuel systems may correspond to the point at which the condition is not recoverable. This is sometimes referred to as an "escalation point;" e.g. a point at which the addition of water to the vessel can no longer provide sufficient cooling to halt the accident progression or could make the situation worse. At this point mitigating actions would not be expected to be effective. For a specific reactor system design and fuel-cladding system it would be useful to identify a success criterion that links "fuel coping time" to a quantifiable reactor condition, above which the accident progression would be irreversible. Such conditions or thresholds could be applied to peak cladding temperature, percent oxidation of the cladding, cladding ductility, amount of hydrogen generated, etc. Such limitations are included in the NRC regulations (i.e. 10CFR50.46) for the current $\mathrm{UO}_{2}$ - $\mathrm{Zr}$ alloy fuel system.

"Metrics" describe a set of technical bases by which multiple concepts can be fairly evaluated against a common baseline and against one another. In some cases this may equate to a specific quantitative target value for selected properties or behaviors. "Metrics" can also describe a clear technical methodology for evaluation that can be used to rank concepts. Because of the complex multiphysics behavior of nuclear fuel rods and the large set of performance requirements that must be met, the latter definition is adopted for the evaluation of candidate ATF designs (Bragg-Sitton et al., 2013, 2015, 2016). In the overall EGATFL Systems Assessment Task Force report, cladding metrics are divided into two separate sections: (1) primary material properties inherent to the material, which are described by single quantified values, and (2) material behavior observed through standardized tests or experiments, which are mainly described by material laws used in modeling. Standardized tests are not intended to analyze fully the material behavior, but to provide decision makers with sufficient information to perform a prioritization of the various cladding material solutions within a specific fuel rod design. To fully characterize the materials and obtain sufficient data for licensing of the various cladding solutions, complementary tests in addition to those recommended here will be necessary. Fuel performance under normal operating conditions and the potential enhanced accident tolerance of a specific ATF concept can be estimated from the fuel behaviors determined from material properties. Key material properties fall into several categories, including thermal, mechanical, chemical, and neutronic properties. Quantification of target values for the various attributes/properties is extremely challenging due to the complex interrelationship among properties. Hence, it is important to consider the integrated effects of the material properties for each advanced fuel design.

The economics of a proposed ATF concept should be evaluated to determine the potential of the fuel system being adopted by industry. Note, however, that it is difficult to assess early in the development of new materials due to significant uncertainty in material and fabrication costs during this development phase and enhanced safety performance is the primary driver for ATF rather than economics. Hence, separation of economic evaluation from the technical performance and safety assessment is likely necessary to allow for prioritization of concepts for further development. The technical performance data will provide more information for future assessment of the overall economics of the proposed fuel system, which may differ in each country as a function of the regional energy markets. It is noted that it is of significant importance to maintain economic viability for new fuel concepts with respect to additional costs (e.g., fabrication) and potential cost reductions realized through improved performance (e.g., additional margins for higher burnup, extended cycle operation and power upgrades, reduced waste) or increased safety margin. Note that this increased performance and safety 
margin may, in turn, be utilized to derive an economic benefit in terms of plant equipment or resource elimination, or risk reclassification, depending on the regulatory landscape of the particular country.

\subsection{Technology Readiness Level}

Definition of technology readiness levels (TRLs) for fuel and cladding were presented at the March 2015 EGATFL meeting by representatives from the U.S., the U.K., and Japan; the TRL definition report issued by the NEA Expert Group on Innovative Fuels was also summarized. The Working Party on Fuel Cycle (WPFC) Expert Group on Innovative Fuels issued a definition of Technology Readiness Level (TRL) applicable to fuels for transmutation purposes. This information is included in the state-of-the-art report published in 2014 (available at this link https://www.oecd-nea.org/science/pubs/2014/6895-reportinnovative-fuels.pdf ). The specificity of the analysis carried out by the Innovative Fuels Expert Group was to take into account all possible combinations for fabrication (materials quality, materials quantity) and in-pile performance (test environment, test size), leading to a quite complete characterisation of possible levels of maturity. Members of the EGATFL Systems Assessment Task Force agreed to make minor adaptations to the TRL definition elaborated by the Innovative Fuels Expert Group such that it is fully applicable to ATF candidates.

Technology Readiness Levels (TRLs) are a means of measuring technology maturity, providing a degree of standardization and allowing comparison between different technologies. Originally defined by the United States National Aeronautics and Space Administration (NASA) (Mankins, 1995, NASA 2012), TRLs have been adopted by many industries and governments around the world including the UK, USA and EU governments, who now routinely consider TRLs when evaluating technology investment proposals.

The TRL scale traditionally has 9 levels. As the technology matures from TRL 1 to TRL 9, it moves from a scientific idea through to a fully developed application that has demonstrated its usefulness by being deployed in operational situations. Because the deployment of a new nuclear fuel form requires lengthy and expensive research, development, and demonstration, application of the TRL concept to advanced fuel development is very useful as a management and tracking tool. The present work by the EGATFL includes an additional component for the maturity of fuel performance codes to support the new fuel system.

Fabrication Process Maturity, which measures how well the fabrication process is understood and validated.

Fuel Performance Maturity, which measures how well the in-pile performance of the fuel is understood and validated.

Performance Code Maturity, which measures the applicability of available fuel performance codes or development and validation of a new fuel performance code for the specific fuel system.

A comprehensive TRL definition should include classification for each of these elements. For example, a mature fabrication process tested at very large scales for novel fuels with large uncertainties in its performance should be differentiated from a mature fabrication process for existing fuels. As shown in Figure 1, there are two key attributes that are important in assessing the TRL for the fabrication process and performance maturity evaluation elements. 


\section{Figure 1. Summary of TRL evaluation elements and attributes}

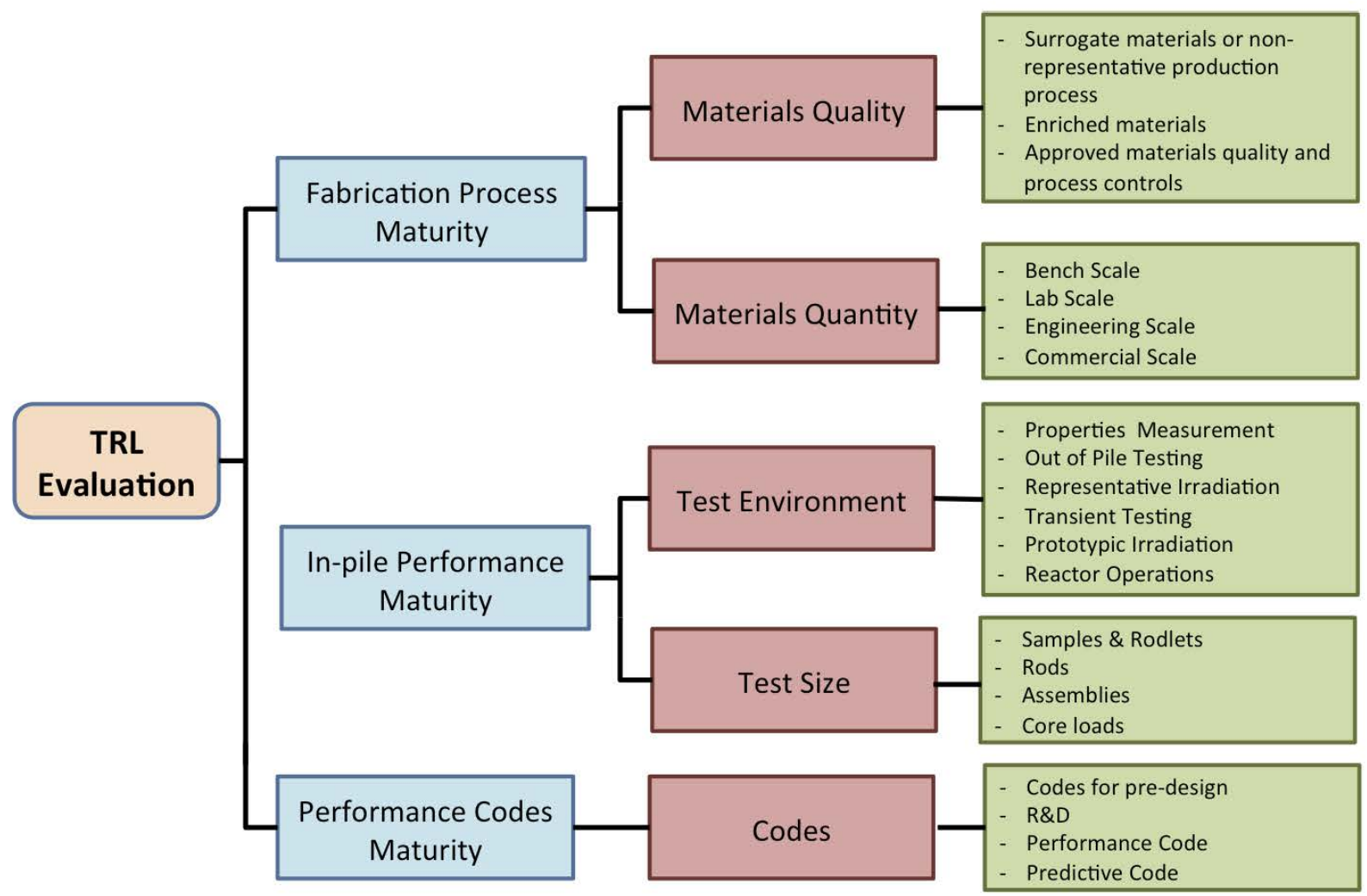

Figure derived and modified from OECD (2014) and Carmack et al. (2017)

\subsection{Definition of Illustrative Scenarios}

Two key illustrative scenarios are proposed by the international community for application to general water-cooled reactor concepts to assess potential performance enhancements relative to the current standard fuel system. These scenarios are identified to bound the range of design extension conditions; they are not intended to be overly prescriptive or specific to a particular facility design. Modeling of these scenarios should utilize the appropriate initiating event, then be allowed to carry through to the point of core failure.

Note that the proposed scenarios assume no operator actions are taken or that the actions taken are unsuccessful. The authors of the EGATFL Systems Assessment report recognize that plants are required to have emergency operating procedures and severe accident mitigation guidelines, and, in addition, industry has developed the capability for additional offsite support and equipment through FLEX. ${ }^{2}$ These actions have been developed and implemented for the $\mathrm{UO}_{2}$-Zircaloy fuel system currently employed. For some operator actions, the timing, actuation criteria, limits, flow rates, etc. may vary based on the fuel system employed. Furthermore, when simulating operator actions, assumptions in action, timing, success/failure, flow-rates, durations, locations, etc. must be made. These factors confound simulation of operator actions and the comparison between different fuel systems. Therefore, recommended 'hands-off' accident scenarios are described herein for initial comparison of candidate ATF concepts to avoid the

\footnotetext{
${ }^{2}$ See http://safetyfirst.nei.org/industry-actions/flex-the-industry-strategy-to-enhance-safety/, accessed April 5, 2017.
} 
complications described above and to provide more clear and direct comparison between fuel system options.

The international community has selected two scenarios for ATF evaluation that are applicable to general reactor designs:

1) Station Blackout (SBO): High pressure scenario; evaluation taken to the point of reactor pressure vessel failure

2) Large-break LOCA (LBLOCA): Low pressure scenario (high decay heat at loss of coolant)

Simulation of these scenarios should be conducted using a PWR, BWR, or VVER model, as appropriate to the country conducting the evaluation. Illustrative scenarios should be considered standard, baseline scenarios for the comparison of a candidate ATF concept to the standard $\mathrm{UO}_{2}-\mathrm{Zr}$-alloy fuel system that is currently employed (using the appropriate alloys, enrichment, etc. for the reactor type being simulated) and for comparison of multiple ATF concepts to one another.

As noted above, the proposed scenarios are intended to provide bounding cases for fuel performance. It is expected that each country or development team will utilize fuel performance and system analysis codes that are accepted within the associated organization to conduct these evaluations. See the U.S. Nuclear Regulatory Commission website for additional information on the State-of-the-Art Reactor Consequence Analyses (SOARCA) project, which provides additional information on accident scenario definition and accident analysis. ${ }^{3}$ All ATF evaluations under the selected accident conditions should be allowed to progress to the point of core failure in the analysis. This allows one to estimate the potential increase in coping time that might be offered by candidate ATF concepts and to assess potential outcomes should failure occur (e.g. if the fuel fails, how does it fail?). Pressure is a significant parameter in the accident progression, as reflected by the selection of both a high-pressure and low-pressure scenario. Following completion of bounding analyses, it is recommended that researchers perform parametric studies for these illustrative scenarios to develop a better understanding of the impact of additional variables. Such parametric studies could include variation of the point in the operating cycle that the accident occurs (e.g., how much burnup has been accumulated in the fuel?) and the time after reactor scram that core cooling is lost. Additionally, one should note that while analyzing scenarios with "no mitigating action" simplifies the analyses and likely provides a bounding result, it must be recognized that the performance of specific ATF concepts may depend on the mitigating actions available and the degree of reliance on their performance during specific accidents. Hence, once a leading ATF candidate is selected, utilities planning to adopt the new fuel type must apply all standard accident analyses for the specific plants that will use the fuel, with available mitigating actions applied.

\subsection{Fuel Performance and System Codes}

Fuel performance and system codes that can be used to evaluate accident tolerant fuel performance, can be modified to evaluate ATF concepts, or are under development are briefly summarized in the full EGATFL Systems Assessment Task Force report. Current limitations of the identified codes, data required to run these codes, and availability of the identified codes to other organizations or countries is included.

Standard evaluation of ATF concepts includes fuel performance analysis (neutronic, thermalhydraulic) and detailed systems analyses. A standard suite of tools is typically used for initial screening analyses, including infinite lattice calculations to estimate basic concept feasibility and three-dimensional

\footnotetext{
${ }^{3}$ See https://www.nrc.gov/about-nrc/regulatory/research/soar.html, accessed May 26, 2017, last updated March 2015 .
} 
core analysis to assess thermal hydraulics, temperature feedback, etc. Work is currently being conducted in the U.S., France, Japan, Republic of Korea, and Switzerland to develop advanced modelling and simulation tools and to incorporate ATF properties and behavioural characteristics. Additionally, existing severe accident analysis tools are being modified to incorporate ATF characteristics. Although some of the tools are limited in fidelity, particularly with regard to ATF concepts for which little property and behavioural data is available, they do provide initial, sometimes qualitative, estimates of performance for these concepts.

Discussion among the EGATFL members has identified additional codes that are being utilized for ATF analysis. Many of these tools are limited in their application to ATF concepts at present, but additional data that will be made available from ongoing research programs will significantly enhance these capabilities. ${ }^{4}$ In many cases companies and organizations select their own internal tools to conduct fuel performance, system, and severe accident analyses. The overall trends observed for materials using these different codes should be studied; the EGATFL task force activities will not attempt to benchmark codes against one another.

\section{IRRADIATION FACILITIES FOR IN-PILE TESTING OF ATF MATERIALS}

Several research reactor facilities around the world are planned for use in irradiation testing of ATF cladding and fuel materials. Applicable facilities for steady state and transient testing are summarized in the full Systems Assessment Task Force report. This summary is not intended to be comprehensive of all potential testing facilities, but includes those facilities that are currently operating in the NEA member and observer countries that are a part of the EGATFL. Facilities summarized in the report include:

- Advanced Test Reactor (ATR) - INL, U.S.

- Transient Reactor Test Facility (TREAT) - INL, U.S.

- High Flux Isotope Reactor (HFIR) - ORNL, U.S.

- BR-2 Materials Test Reactor (Belgium)

- Halden Reactor Project (Norway)

- CABRI (France)

- Jules Horowitz (France)

- Nuclear Safety Research Reactor (NSRR, Japan)

- HANARO (Republic of Korea)

- HFR Materials Test Reactor (Netherlands)

- LVR-15 Research reactor (Czech Republic)

- The China Mianyang Research Reactor (CMRR, China)

\section{SUMMARY}

This report provides a brief summary of the activities conducted within the Systems Assessment task force (TF1) for the OECD/NEA Expert Group on Accident Tolerant Fuels for LWRs and of the items included in the final TF1 deliverable report. Note that the other task forces within the EGATFL on Cladding and Core Materials (TF2) and Fuel Concepts (TF3) will produce a combined state-of-the-art report on the materials under development across the NEA member countries and involved observer countries (e.g. China). These state-of-the-art reports are targeted for final approval at the EGATFL meeting to be held in November 2017.

\footnotetext{
${ }^{4}$ Data on fuel and cladding material properties and behaviours will be included the State-of-the-Art report for fuel and cladding produced by EGATFL Task Forces 2 and 3.
} 


\section{References}

Bragg-Sitton, S.M., et al. (2013), Enhanced LWR Accident Tolerant Fuel Performance Metrics, INL/EXT-13-29957, Idaho National Laboratory, prepared for the U.S. Department of Energy Advanced Fuel Campaign.

Bragg-Sitton, S.M., B.J. Merrill, J. Hales, N. Brown, M. Todosow, and K. Robb (2015), "Evaluation of Enhanced Accident Tolerant LWR Fuels," in Proceedings of Top Fuel 2015, Zurich, Switzerland.

Bragg-Sitton, S.M., Todosow, M., Montgomery, R., Stanek, C.R., Montgomery, R., and Carmack, W.J. (2016), Metrics for the Technical Performance Evaluation of Light Water Reactor Accident Tolerant Fuel, Nuclear Technology, 195(2), p. 111-123, August 2016.

Carmack, W.J., L.A. Braase, R.A. Wigeland, and M. Todosow (2017), Technology readiness levels for advanced nuclear fuels and materials development, Nuclear Engineering and Design, 313 (2017), pp. $177-184$.

Mankins, J. C. (1995), Technology Readiness Levels, Advanced Concepts Office, Office of Space Access and Technology, National Aeronautics and Space Administration.

NASA (2012), Technology Readiness Levels, available online at http://www.nasa.gov/ directorates/heo/scan/engineering/technology/txt_accordion1.html, accessed 5 April 2017.

OECD (2014), State-of-the-art Report on Innovative Fuels for Advanced Nuclear Systems, Appendix A: Definition of technology readiness levels (TRLs) for transmutation fuel development, NEA No. 6894, Nuclear Science, 2014. 


\section{Appendix A \\ Outline of Deliverable Report \\ Assessment of Light Water Reactor Accident Tolerant Fuel: \\ Evaluation Metrics and Illustrative Scenarios}

\section{INTRODUCTION}

\section{ATF DESIGN CONSTRAINTS AND DESIRED ATTRIBUTES}

\section{DEFINITION OF EVALUATION METRICS AND RELATED TESTING}

\subsection{Cladding Materials}

3.1.1. Desired Cladding Properties, Behavior, and Performance

3.1.2. Definition of the Metrics

3.1.3. Primary Material Properties for Initial Evaluation

3.1.4. Standard Tests to Evaluate Key Behavior and Performance

\subsection{Fuel Materials}

3.2.1. Desired Performance, Properties, and Behavior

3.2.2. Fuel Characterization: Standard Tests for Normal Operation and Accident Conditions

\subsection{Considerations for the Fuel / Cladding System}

3.3.1. Fuel System Chemical Interactions

3.3.2. Pellet/Cladding System Behavior, Including Irradiation Testing Protocol

\section{APPLICATION OF EVALUATION METRICS / PATH FORWARD}

5. TECHNOLOGY READINESS LEVELS

5.1. Definition of TRLs Relative to Nuclear Fuel

5.2. Assignment of TRL Definitions

5.3. TRL Summary

6. DEFINITION OF ILLUSTRATIVE SCENARIOS FOR EVALUATION

6.1. High Pressure Scenario: Station Blackout

6.2. Low Pressure Scenario: Large Break Loss of Coolant Accident

7. APPLICABLE MULTI-PHYSICS CODES FOR FUEL PERFORMANCE EVALUATION AND SYSTEM IMPACT

7.1. Standard Screening Analyses for ATF Concepts

7.1.1. Nuclear Data Requirements

7.1.2. Initial Neutronic Screening Analyses

7.1.3. Three-Dimensional Core Analyses

7.1.4. Transient Analyses

7.1.5. Fuel performance codes

7.2. Advanced Fuel Performance Modeling Tools 


\subsubsection{MOOSE/BISON/MARMOT}

7.2.2. FALCON

7.2.3. TRANSURANUS

7.2.4. PLEIADES/ALCYONE

7.2.5. FEMAXI

7.2.6. MACROS

7.3. Analysis of Severe Accident Behavior

7.3.1. MELCOR

7.3.2. MAAP

7.3.3. ASTEC

7.3.4. SOCRAT

\subsection{Vendor Evaluation of ATF Concepts}

8. IRRADIATION FACILITIES FOR IN-PILE TESTING OF ATF MATERIALS

8.1. Advanced Test Reactor (ATR) - INL, U.S.

8.2. Transient Reactor Test Facility (TREAT) - INL, U.S.

8.3. High Flux Isotope Reactor (HFIR) - ORNL, U.S.

8.4. BR-2 Materials Test Reactor (Belgium)

8.5. Halden Reactor Project (Norway)

8.6. CABRI (France)

8.7. Jules Horowitz (France)

8.8. Nuclear Safety Research Reactor (NSRR, Japan)

8.9. HANARO (Republic of Korea)

8.10. HFR Materials Test Reactor (Netherlands)

8.11. LVR-15 Research reactor (Czech Republic)

8.12. The China Mianyang Research Reactor (CMRR, China) 